\title{
Non-Stress Test
}

National Cancer Institute

\section{Source}

National Cancer Institute. Non-Stress Test. NCI Thesaurus. Code C92836.

A non-invasive test usually done during the third trimester to check for fetal well being. It

is performed using an external fetal heart rate monitor to assess the fetal heart rate response to fetal movements. 